\title{
METODE-METODE PERUMUSAN DAN PENELITIAN PSIKOLOGI ISLAMI
}

\author{
H. Fuad Nashori \\ Universitas islam indonesia
}

\begin{abstract}
Tulisan ini bermaksud menyajikan metode-metode yang dapat dipergunakan dalam upaya perumusan dan penelitian psikologi Islami. Menurut penulis, metode-metode yang pertu dikembangkan datam upaya perumusan psikologi islami adalah metode keyakinan, metode rasiosinasi, integrasi metode keyakinan dan rasiosinasi, serta metode otoritas. Untuk penelitian psikologi islami, menurut penulis, metode yang perlu dikembangkan seiain selain metode ilmiah adalah metode intuisi, dan metode eksperimen spirilual.

Penulis menekankan bahwa penggunaan metode yang beragam in dikarenakan ilmu pengetahuan Islam senantiasa berupaya untuk menerapkan metode-metode yang berlainan sesual dengan watak subjek yang dipelajari serta cara-cara memahami subjek tersebut.
\end{abstract}

Kata Kuncl : psikologi Islami, metode rasiosinasi, metode keyakinan, metode intuisi, metode otoritas, metode eksperimen spiritual

H. Fuad Nashori, lahir di Mojokerto pada 23 Desember 1970, adalah direkiur Yayasan Insan Kamil Yogya dan dosen Fakultas Psikologi UII. Meminati pemikiran dan penelitian seputar psikologi Islami, psikologi agama, psikologi sosial dan. psikologi perkembangan. Saat ini sedang menempuh pendidikan program pasca sarjana di Universitas Gadjah Mada (dengan minat utama psikologi sosial).

\section{PENGANTAR}

C alah satu tema penting dalam wacana (discourse) psikologi Islami yang belakangan mendapat banyak sorotan adalah masalah metode yang dipergunakan psikologi Islami dalam merumuskan teori maupun dalam mengungkap fakta. Tema ini secara khusus diangkat sebagai terna Simposium Nasional Psikologi Islami || 7996 yang berlangsung di Fakultas Psikologi Universitas Padjadjaran (Bandung) maupun dalam Dialog Nasional Pakar Pssikologi Isiami 1997yang berlangsung di Fakultas Psikologi Universitas Danl! Ulum (Jombang). Tulisan ini difokuskan pada usaha untuk 
menjawab pertanyaan (a) metode apa yang dipergunakan untuk merumuskan psikologi Islami dan (b) metode apa pula yang dipergunakan untuk mengungkap fakta (empiri, kenyataan) yang terjadi pada diri manusia?

Hal pokok yang hendak penulis sampaikan adalah psikologi Islami - sebagaimana ilmu pengetahuan lainnya - menggunakan metode yang lebih beragam dibanding sains Barat. Kalau sains Barat menggunakan satu metode saja, yaitu melode itmiah (scientific method), maka ilmu pengetahuan Islam menggunakan beberapa metode sekaligus. Hal ini sebagaimana diungkapkan cendekiawan Muslim Malaysia Osman Bakar dalam buku Tauhid dan Sains (Bakar, 1996:24) . a menuturkan balwa ilmu pengetahuan Islam senantiasa berupaya untuk menerapkan metode-metode yang berlainan sesuai dengan watak subjek yang dipelajari dan cara-cara memahami subjek tersebut. Para ilmuwan Muslim. dalarn mengembangkan beraneka ragarn cabang illmu pengetahuan, telah menggunakan setiap jalan pengetahuan yang terbuka bagi manusia, dari rasiosinasi dan interpretasi kitab suci hingga observasi dan eksperimentasi.

Secara berurutan, tulisan ini akan mengungkap bagaimana pandangan dunia Islam (Islamic worid view) tentang realitas dan metode-metode yang dipergunakan untuk memahami dan memperlakukan realitas itu. Tentang metode yang digunakan psikologi Islami, penulis mencoba menguraikan lebih lanjut tenlang metode yang dipergunakan dalam perumusan (teori) dan metode yang dipergunakan dalam penelitian. Metode-metode yang dipergunakan dalam penerapan psikologi islami tidak dibahas dalam tulisan ini.

\section{PANDANGAN DUNIA ISLAM TENTANG REALITAS}

Ahli futurologi, Ziauddin Sardar (Ancok \&Suroso, 1995:134), mengungkapkanbahwa upaya menghasilkan ilmu pengetahuan Islam harus dimulai dengan membangun pandangan dunia Islam (islamic world view). Pandangan dunia Islam berupaya mengungkapkan bagaimana pandangan Islam tentang realitas atau tentang "yang ada", Dalam bagian ini akan diungkapkan pandangan dunia Islam dan pandangan dunia sains modern.

Ahli-ahli Islam dari kalangan sufi berpendapat bahwa đunia makrokosmos (maksudnya seluruh tatanan ciptaan Tuhan) dan juga mikrokosmos (tatanan ciptaan Tuhan padadiri manusia) terdiri atas tiga keadaan fundamental, yaitu keadaan materiil atau bendawi, keadaan psikis atau animistik, dan keadaan spiritual atau malakuti. Dunia materiil, yang disebut juga đunia kasar, dengan segera diliputi dan didominasi oleh wilayah psikis, yang juga disebut sebagai dunia hatus. Kedua dunia ini bersama-sama membentuk wilayah "alam". Dunia malakutilah yang mengatur semua hukum alam di wilayah kasar dan wilayah halus itu.

Sementara ahli-ahli lain mengungkapkan bahwa realitas makrokosmos maupun mikrokosmos dapat dibagi menjadi tiga bagian, yaitu wilayah yang teramati (observable area), wilayah yang terpikirkan (conceivable area), dan wilayah yang tak terpikirkan (unconceivable area) (Nashori. 1997:10). Observable area adalah wilayah realitas yang dapat diketahui oleh (panca) indra manusia, yang terdiri atas pengelihatan, pendengaran, pengecapan perasaan lahir, dan penciuman. Conceivable area adalah witayah realitas yang dapat dipikirkan dan dirasakan oleh manusia. Sementara unconceivable area adalah wilayah realitas yang tidak dapat diindra, dipikirkan. 
dan dirasakan oleh manusia.

Berbeda dengan ilmu pengetahuan islam yang merangkul seluruh realitas, sains moderen membatasi ruang lingkup dirinya hanya pada benda-benda yang bersifat indrawi, yaitu dunia yang dapat diobservasi oleh indra. Henry Margenau (Mulyadhi Karta negara, 1997: 4), seorang fisikawan, guru dan juga penasihat pemerintahan dan industri. dalam buku The Scientist memberi ruang operasi ilmuwan pada apa yang disebut observable facts, suatu dunia pengalaman terbatas yang hanya mengizinkan pencerapan-pencerapan yang kita terima secara langsung melalui indra, ditambah dengan proses murni logika untuk memilih, memutuskan, dan memberikan penalaran.

Dari keterangan di atas, bisa dilakukan perbandingan bahwa ilmu pengetahuan Islam bukan hanya bekeria pada wilayah yang teramati (observable area), tapi juga bekerja pada wilayah yang terpikirkan (conceivable area) dan wilayah yang tidak terpikirkan (unconcervablearea). Tuhan, hari akhir, makhluk halus (seperti jin, setan, iblis), dan seterusnya adalah hal-hal yang berada pada wilayah yang tak terpikirkan (unconcejvable ar ea). limu pengetahuan Islam termasuk di dalamnya psikologi isiami bukan hanya menggunakan indra dan akal saja dalam merumuskan suatu konsep, tapi yang tak kalah strategisnya adaliah mempergunakan intuisi dan wahyu.

Penggunaan indra, akal, intusi danwahy adalah kons ekuensi logis dari luasnya bentangan wilayah kajian ilmu pengetahuan Islam. Sebagai misal kenyataan tentang bahwa iblis selalu menggoda manusia (antara lain mereka akan selalu benssaha menjadikan hal yang buruk tampak sebagai hal yang baik, sebagaimana tertulis dalam CS al-Hijir, 15: 39) hanya dapat diketahui dengan menggunakan wahyu (dalam hal ini al-Qur'an).

\section{METODE-METODE PERUMUSAN PSIKOLOGI ISLAMI}

Dalam upaya merumuskan konsepkonsep psikologi islami, penggunaan akal pikiran dan wahyu dipandang sebagai kemestian yang harus dilakukan.

\section{Metode Keyakinan}

Dalam metode keyakinan (method of tenacily), seseorang meyakini kebenaran sesuatu tanpa keraguan apapun di dalamnya. Dalam metode ini, yang absah dijadikan sebagai sumber yang diyakini kebenarannya adalah wahyu llahi, khususnya al-Qur'an dan al-Hadits. Penempatan wahyu llahi sebagai sumber kebenaran dan sumber pengetahuan berangkat dari keyakinan bahwa Tuhan (//ah) adalah sang pencipta kehidupan ini. Sebagai pencipta, Dia tentu mengetahui seluk beluk diri dan makhluk ciptaannya itu dalam suatu wahyu.

Tidak kurang dari itu, Dia juga selalu melindungi wahiyu itu agar dalam keadaan otentik. Penjelasan bahwa Allah memberikan jaminan tentang kesucian dan kemurnian al-Qur'an selama-lamanya diungkapkan sendiri oleh Tuhan: Sesungguhnya Kami-lah yang menurunkan al-Qur'an dan sesungguhnya Kami benar-benar memeliharanya (QS al-Hiji 15: 9).

Salah satu cri utama ilmu pengetahuan Islam - dalam hal ini psikologi Islami adalah wahyu Tuhan ditempatkan of atas rasio. Wahyu memperoleh kedudukan yang paling tinggi. Dalam upaya mengembangkan ilmu pengetahuan Islam - dalam hal ini untuk merumuskan konsep-konsep psikologi Isiami - maka yang akan dilakukan adalah menjadikan wahyu llahi sebagai sumber kebenaran mutlak.

Mengingat bahwa dalam kenyataannya wahyu llahi yang berada dalam kitab suci tidak biasa dijadikan sumber untuk merumuskan ilmu pengetahuan moderen, maka 
gagasan untuk menjadikan wahyu ilahi yang berupa kitab suci tidak selamanya dapat diterima oleh ilmuwan Muslim (Fuad Nashori, 1997). Menurut Hanna Djumhana Bastaman (1996: 39-40), salah satu persoalan pokok adalah bagaimana mengembangkan sikap kesetujuan dari psikolog Muslim untuk mau menjadikan al-Qur'an, dan al-Hadist sebagai rujukan utama untuk mendapatkan patokan kebenaran ilmiah psikologi d atas akal pikiran manusia.

Di kalangan ilmuwan kontemporer. usaha untuk menggunakan metode keyakinan dengan menjadikan ayat suci sebagai sumber pengetahuan dilakukan Feyerabend dalam Against Method (1982:30).

\section{Metode Rasiosinasi}

Berbeda dengan sains Barat yang meninggikan peran rasionalitas, maka ilmu pengetahuan Islam - dalam hal ini psikologi Islami -berpandangan bahwa manusia harus mempergunakan rasionalitas sambil menyadari keterbatasannya. limu pengetahuan Islam menekankan pentingnya mempergunakan rasio, tapi tidak memperkenankan kita menganut rasionalisme. Dikatakan oleh Fritjof Schuon (1980:36) bahwa rasionalisme itu keliru bukan karena la berupaya untuk mengekspresikan real:tas secara rasional, sejauh hal itu memungkinkan, tetapi karena ia berupaya merangkul seluruh realitas ke dalam alam rasio, seakan-akan ini sesuai dengan prinsip segala sesuatu.

Walaupun demikian, sambil memperhatikan keterbatasan yang dimiliki oleh akal-pikiran atau rasio, maka manusia dianjurkan untuk mempergunakan secara optimai. Ungkapan-ungkapan ayat-ayat suci al-Qur'an (dan al-Hadist) yang berisi anjuran mempergunakan akal pikiran menunjukkan bahwa akal pikiran perlu didayagunakan secara optimal. Dan of antara tandatanda kekuasan-Nya ialah dia menciptakan untukmu istri-istri dari jenismu sendiri, supaya kamu cenderung dan mo rasa tentram kepadanya, dan diciptakan of antara kamu rasa kasih dan sayang. Se sungguhnya pada yang demikian itu benarbenar terdapat tanda-tanda bagi kaum yang berpikir (QS ar-Ruum, 30:12).

\section{Integrasi Metode Keyakinan dan Rasiosinasi}

Kalau psikologi Islami diartikan sebagai ilmu pengetahuan tentang aspek dalam diri manusia yang kerangka konsepnya, metodologi, dan pendekatannya dibangun dengan semangat islam dan bersandarkan pada sumber-sumber formal Islam (Ancok \& Nashori, 1995: 139), maka pola yang paling tepat untuk dipergunakan adalah membangun konsep psikologi berdasarkan islam, dalam hal ini al-Quran dan ai-Hadist. Dengan demikian, salah satu tugas terpenting adalah mencoba memahami al-Qur'an dan al-Hadist dengan pendekatan ilmu tafsir. Penulis berpendapat bahwa metode yang biasa dipergunakan oleh ilmu tafsir dapat diambil alih oleh psikologi yang lain.

Dalam ilmu tafsir dikenal berbagai macam metode, yaitu metode tafsir tahlili, metode tafsir ijmali, metode tafsir muqaram, dan metode tafsir mawdiu'i. Salah satu metode tafsir yang banyak dipergunakan adalah tafsir bi al-ra'yi. Tafsir bi al-ra'yi, ialah menafsirkan al-Qur'an dengan kekuatan penalaran dan unsur-unsur keilmuan yang berkembang di dunia Islam yang memang berkaitan dengan bunyi teks serta isyaratisyarat ilmiah yang datang dari al-Qur'an sendiri. Dengan metode semacam ini dimungkinkan bagi para pemikir psikologi Islami untuk menuangkan pemikirannya dalam naungan wahyu llahi. Kalau terdapat pertentangan antara pemikirannya dengan teks-teks wahyu llahi, maka hai yang harus 
dilakukannya adalah menyadari keterabatasan pikiran manusia dan superioritas wahyu llahi. Salah satu karya besar tafsir jenis ini adalah The Holy Al-ouran karya Yusuf Abdullah Ali. Contoh tafsir lain dalam jenis ini adalah $T$ tosir al-Azharkarya Hamka.

\section{Metode Otoritas}

Dalam method of authority, seseorang menyandarkan kepercayaan kepada orangorang yang memiliki banyak pengalaman atau pengetahuan dalam suatu bidang tertentu. Karena pengalamannya itulah akhirnya kewenangan (authorily) diraihnya.

Dalam ilmu tafsir dikenal apa yang disebut sebagai tafsir bi al-ma'tsur. Dalam metode ini seseorang menalsirkan al-Qur'an, dengan merujuk kepada penjelasan Rasulullah terhadap ayat-ayat tertentu dengan alasan bahwa penafsiran yang paling benar tentu saja datang dari Rasulullah Muhammad dan para sahabat dekatnya. Itulah sebabnya metode ini dinamakan tafsir bi al-ma'tsur atau menafsirkan al-Qur'an berdasarkan tradisi Nabi dan para sahaba! dekatnya. Di antara tafsiryang menggunakan metode ini adalah Jam' al-Bayan $f$ tafsir al-Qur anoleh lbnuJariral-Thabari dan tafsir al-Quran al-Adzim karangan Ibnu Katsir (Hidayat, 1996). Salah satu keunggulan metode ini adalah kita diajak untuk menelusurf kembali serta diperkenalkan peristiwa-peristiwa yang terjadi d seputar turunnya alQur'an dan suasana sosial-psikologis Rasulullah dan para sahabat sewaktu alQur'an diturunkan. Hanya saja jika tidak disertai sikap kritis-reflektif narasi historis yang disajikan sering tidak akurat dan lagi orientasi intelektual-psikologis dalam mendekati al-Qur'an lalu ditarik secara kuat ke belakang.

Dalam upaya merumuskan psikologi Islami, sumber otoritas yang dapat dijadikan rujukan adalah Nabi dan para orang- orang alim (ulama'). Orang-orang yang memiliki ilmu pengetahuan dan sekaligus mengalami peristiwa-peristiwa penting dalam hidupnya dapat dijadikan sumber pengetahuan untuk mengetahui realitas yang tidak tampak oleh mata.

\section{METODE-METODE PENELITIAN PSIKOLOGI ISLAMI}

Suatu teori akan teruji kehandalannya bila mampu mengenali dan memahami realitas d lapangan. Karena itu diperlukan metode-metode penelitian yang mampu melakukan peran $₫$ atas. Cara memahami data, fakta atau realitas yang ada dalam sains Islam sangat beragam, Dari metode observasi, metode eksperimen, hingga eksperimen spiritual diakui keberadaannya dalam ilmu pengetahuan Islam. Dalam ilmu pengetahuan Islam semua metode yang beragam itu dianggap sebagai jalan atau cara yang sah untuk memahami alam/realitas dalam bidang penerapannya masingmasing. Walaupun demikian, tidak ada sains yang dapat mengklaim dirinya sepenuhnya Islam dalam bentuk dan karaktemya bila metodologi yang digunakan tetap berakar dari paradigma sains moderen.

Secara garis besar, psikologi Islami dkembangkan dengan menggunakan metode-meode ilmiah (method of science), metode keyakinan (method of tenacily), metode otoritas (method of authoriy), dan metode intusisi (method of intuition). Dalam perumusan teori kita perlu menekankan penggunaan metode keyakinan. Untuk mengungkap kenyataan di lapangan, perlus dilakukan penelitiandengan menggunakan metode ilmiah, metode intuisi, eksperimen spiritual, dan metode lain yang dipercayai kehandalannya. Dalam praktik perlu banyak digunakan semua metode, yaitu mebode ibadah, metode otoritas, dan metode keyakinan. 


\section{Metode IImiah}

Menurut M.D. Dahlan (1996), metode ilmiah terdiri atas metode deskriptif dan metode eksperimen. Termasuk metode deskriptif adalah observasi dan riset korelasi.

Dalam beberapa dekade terakhir ini, metode fenomenologi mulai banyak dipergunakan orang. Menurut Hanna Djumhana Bastaman (1997), jika objek yang diliihat mengarah kepada kondisi dan pengalaman ruhani, maka metode fenomenologi akan menjadi sangat tepat. Seseorang yang memiliki pengalaman pribadi yang bersifat subjektif, bahkan terkadang tidak masuk akal atau tidak rasional atau tidak objektif, dapat diteliti pengalamannya dengan fenomenologi. Metode fenomenologi berusaha menjelaskan dan mengungkapkan sesuatu menurut suatu fenomena (gejala). Gejala itu yang selanjutnya akan berbicara tentang suatu objek psikologi. Umpamanya, untuk melakukan sebuah penelitian psikologis terhadap dampak dari dzikir yang dilakukan kalang santri, hal itu tidak cukup dengan observasi. Dengan metode fenomenologi, peneliti meminta kepada santri untuk bercerita pengalaman spiritualnya masingmasing. Menurut Bastaman (1997). para psikolog yang kukuh dengan metode ilmiah tidak menyukai metode fenomenologi ini.

\section{Metode Intuls|}

Metode yang tidak populer di kalangan ahli psikologi moderen-dan ahli-ahli sains moderen lainnya - adalah motode intuisi. Sesungguhnya psikologi Islami - dan Islam pada umumnya- mengharapkan agar manusia mempergunakan intuisinya atau hati nuraninya. Apabila melode ini dipakai, maka kemudian yang terjadi adalah kasyaf (ketersingkapan) dan fistuh (ketebukaan). Dalam situasi seperti ini, maka seseorang dapat melihat dengan mata batinnya ke- nyataan-kenyataan yang tak dapat dilinat oleh panca indra. Kemampuan khas yang dimiliki oleh Nabi Khidir (yang mampu mengetahui bahwa seseorang anak dalam perahu suatu saat akan durhaka kepada kedua orang tuannya), Nabi Yusuf (mampu membuka rahasia mimpi), adalah contoh bahwa hati yang tidak tertutup dapat melihat hal-hal yang tidak tampak oleh mata dan tidak terdengar oleh telinga, seperti precognition, retrocognition, dan claivoyance adalah contoh bekerjanya metode Kognisi.

\section{Metode Eksperimen Spiritual}

Tak kurang dari itu, salah satu metode yang dilakukan oleh seseorang yang ingin mengetahui rahasia Tuhan dalam memberlakukan manusia adalah metode eksperimen spiritual. Dalam hal ini, seseorang mencoba membuat perlakuan tertentu dan secara ruhani dia berusaha mengetahui dampak dari perlakuannya. Salah satu contoh ekperimen spiritual adalah seseorang melazimkan diri bangun untuk shalat malam pada jam dua belas. Dia berusaha mengetahui bagaimana rasa hati ini terhadap Tuhan setelah membiasakan diri berbuat demikian. Alhamdulillahi rabbil 'alamin.

\section{DAFT AR PUSTAKA}

Ancok, Djamaludin \& Suroso, Fuad N. 1995. Psikologi Islami. Cetakan kedua. Yogyakarta: Pustaka Pelajar.

Bakar, Osman. 1995. Tauhid dan Sains. Terjemahan dari "Tawhid and Science: Essay on the History and Philosophy of Islamic Science" (Secretariat for Islamic Philosophy and Science \& Nurin Enterprise, Malaysia). Cetakan Kedua. Bandung: Penerbit Pustaka Hidayah. 
Bastaman, Hanna Djumnana. 1996. Integrasi Psikologi dengan Islam. Cetakan kedua. Yogyakarta: Yayasan insan Kamil \& Pustaka Pelajar.

Bastaman, Hanna Djumhana. 1996. Meraih Hidup Bermakna. Jakarta: Paramadina.

Butt, Nasim. 1996. Sains dan Masyarakat Islam. Bandung: Pustaka Hidayah.

Hidayat, Komaruddin. 1996. Memahami Bahasa Agama. Jakarta: Paramadina.

Kartanegara, Mulyadi. 1997. "Menjajaki Kemungkinan Islamisas; Pengetahuan". Dalam Harian Republika 19 Juli 1997.

Kartanegara, Mulyadi. 1997. "Perlukah islamisasi IImu?" Dalam Harian Republika, 19 September 1997.
Nashori, H.Fuad.1997. Psikologi Islami: Agenda Menuju Aksi. Yogyakarta: Penerbit Pustaka Pelajar \& Fosimamupsi.

Nashori, H.Fuad.1997. Menggapai Keunggulan Islam: Khotbah-khotbah Jum'at. Yogyakarta: Pustaka Pelajar \& Yayasan Kasih Al-Arkham.

Nashori, Fuad. 1997. "Visi Psikologi Islamr. Makalah disampaikan dalam "Dialog Nasional Pakar Psikologi Islami", Fakultas Psikologi Universitas Darul 'Ulum, Jombang, 28-30 Novernber 1997.

Schuon, Fritjof. 1980. Lagic and Trancendence Stations of Wisdom Middlesex: Perennial Book

Sukanto MM \& Hasyim , A. Dardiri. 1995. Nafsiologi: Refleksi Analisis tentang Din dan Tingkah Laku Manusia. Surabaya: Risalah Gusti. 